each other, the method of constructing the barrier appears to be successful.

L. BASS

Department of Mathematics,

Lanchester College of Technology, Coventry.

${ }^{1}$ Bass, L., Nature, 198, 982 (1963).

2Debye, P., Polar Molecules (Chemical Catalog Co., New York, 1929).

${ }^{3}$ Debye, P., Ann. Physik, 39, 789 (1912).

4 Frenkel, J., Kinetic Theory of Liquids (Oxford University Press, 1946).

- Bockris, J. O'M., Modern Aspects of Electrochemistry (Butterworths, London, 1954).

' Fleischmann, M. (private communication).

\section{Fluorescence Spectrum of Di-cæsium Uranyl Nitrate}

IN the course of our investigations on radiation effects on cæsium uranyl nitrate $\left(\mathrm{CsUO}_{2}\left(\mathrm{NO}_{3}\right)_{3}\right)$ it was found that the spectrum of di-cæsium uranyl nitrate is not known although the spectra of the corresponding di-rubidium and di-potassium uranyl nitrates are known. Attempts to prepare di-cæsium uranyl nitrate $\left(\mathrm{Cs}_{2} \mathrm{UO}_{2}\left(\mathrm{NO}_{3}\right)_{4}\right)$ do not seem to have bcen successful so far ${ }^{1}$. It has, however, been possible to prepare the salt and examine its fluorescence spectrum which is recorded here.

If an aqueous solution containing cæsium nitrate and uranyl nitrate hexahydrate in the molar ratio of $2: 1$, or slightly higher, is allowed to evaporate it is possible to get either mono-cæsium uranyl nitrate or di-cæsium uranyl nitrate by controlling the temperature at which evaporation occurs. Thus at $26^{\circ} \mathrm{C}$ the crystals which separate out are mostly the well-known pale green crystals of monocæsium uranyl nitrate mixed with a few yellowish-green crystals which can be easily picked out from the bulk of the crystals. If, however, the evaporation is carried out at $10^{\circ} \mathrm{C}$ it is found that only the yellowish-green crystals are obtained. Chemical analysis and X-ray diffraction studies of the yellowish-green crystals thus obtained prove conclusively that they are the di-cæsium uranyl nitrate crystals.

The fluorescence spectrum of the di-crsium salt at $77^{\circ} \mathrm{K}$ which is shown in Fig. 1 consists of an extended system of bands. The structure of the spectrum as indicated in Fig. I is in general similar to that of the monocæsium salt. The symmetric vibration $A$ occurs in several quanta (observed up to four) alone and in combination with a single quantum separately of each of the antisymmetric vibration $B$, the bending vibration $C$ as well as several of the $\mathrm{NO}_{3}$ and the so-called lattice frequencies. Thus $\mathrm{B}, \mathrm{C}, \mathrm{NO}_{3}$ and the lattice vibrations occur only in single quantum either alone or each in combination with one or several quanta of $A$. The $B$ band is more intense than $A$ and the strongest are $A+B, 2 A+B, 3 A+B$, and $4 A+B$ combination bands. The frequencies of vibration of the $\mathrm{UO}_{2}{ }^{++}$ion are, however, different from those of mono-crsium uranyl nitrate and as derived from the fluorescence spectrum are: $857 \cdot 2 \mathrm{~cm}^{-1}(\mathrm{sym} A), 936 \cdot 1$ $\mathrm{cm}^{-1}$ (antisym $B$ ) and $259 \cdot 0 \mathrm{~cm}^{-1}$ (bending $C$ ). The

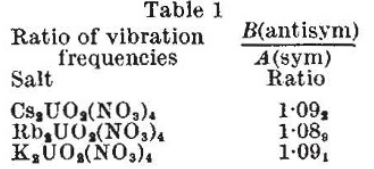

Ratio of vibration frequencies of mono- and di-alkali uranyl nitrates

$\begin{array}{lccc}\text { Vibration } & \begin{array}{c}\text { mono- } \\ \text { di- }\end{array} & \begin{array}{c}\text { mono- } \\ \text { di- }\end{array} & \begin{array}{c}\text { mono- } \\ \text { di- }\end{array} \\ \text { sym) } & 1.03_{1} & 1.03_{1} & 1.00_{6} \\ \text { antisym) } & 1.02_{2} & 1.02_{8} & 1.00_{4}\end{array}$

resonance band, $R$, is at $20,751 \mathrm{~cm}^{-1}(4817 \cdot 7 \AA)$. Certain relevant relations between frequencies of the mono- and di-alkali salts are given in Table 1. The values of vibration frequencies for the various uranyl salts except those of di-cæsium uranyl nitrate are taken from Dieke and Duncan ${ }^{1}$.

\section{R. K. Astindi}

Spectroscopy Division,

R. M. Dixit

Atomic Energy Establishment Trombay, Bombay 28.

${ }^{1}$ Dieke, G. H., and Duncan, A. B. F., Spectroscopic Properties of Uranium Compounds, Nat. Nuclear Energy Ser., Div. 3, 2 (MeGiraw-Hill Book Compounds, Nat. Nuclear Ener.,
Co., Inc., New York, 1949).

\section{Run-off of Cæsium-137 and Strontium-90 from Rivers}

THE factor of weathering must be taken into consideration in the prediction of future radiation dose, either external or internal, caused by the accumulated ground deposits of fission products.

Measurements have been made since 1960 on the concentrations of cæsium-137 and strontium-90 in the River Tonegawa, which has the largest catchment area in Japan. Monthly deposits of these radionuclides were also measured at Kiriu City, which is situated in the vicinity of the sampling station of river water. The results are summarized in Table 1. The concentrations in rain water were calculated by dividing the monthly deposits by the monthly rainfall.

An attempt was made to evaluate the run-off of a radionuclide in terms of the cumulative deposition and the deposition rate on the basis of an expression of the following general form:

$$
C=C_{d}+p_{r} C_{r}
$$

where $C$ is the concentration of a radionuclide in the river water $(\mu \mu \mathrm{c} . / 1),. \widetilde{C}_{r}$ is the concentration of the radionuclide in tho rain water ( $\mu \mu \mathrm{c} . / 1$.) corrected for the evaporation (30 per cent is assumed), $p_{r}$ is a proportionality factor and $C_{d}$ is the concentration of the radionuclide in the river water which was derived from the cumulative deposition. $C_{d}$ may bo assumed to be a function of the cumulative deposition but since its dependence on time during the period of this observation was rather small as compared with that of $C_{r}$, it has been temporarily assumed to bo constant.

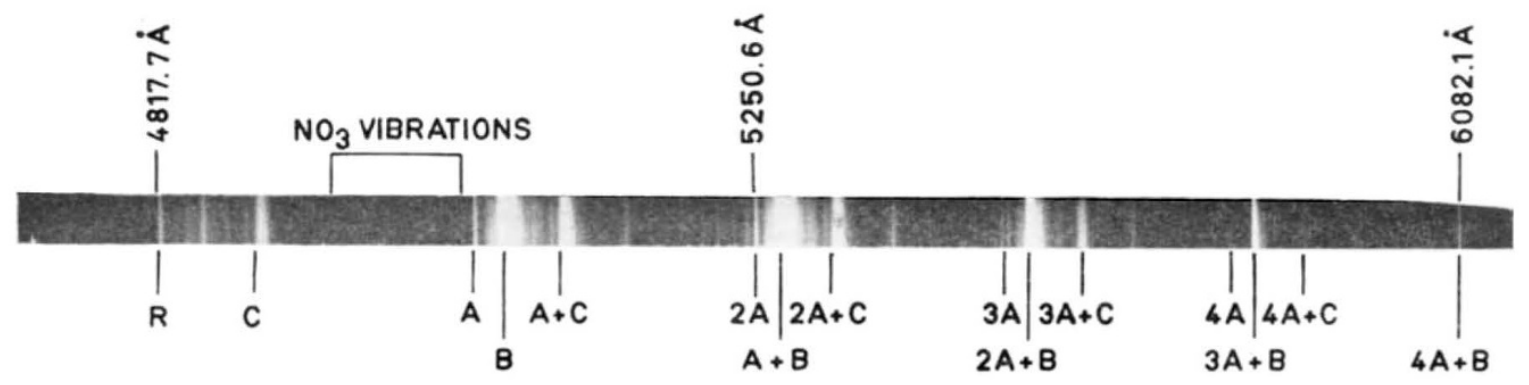

